\title{
Protrusion of the device: a complication of catheter closure of patent ductus arteriosus
}

\author{
J Ottenkamp, J Hess, M D Talsma, T N Buis-Liem
}

\begin{abstract}
Objective-To assess the medium term results of percutaneous transvenous closure of patent ductus arteriosus, in particular with regard to protrusion of the device with or without turbulence of the bloodflow.
\end{abstract}

Design-Clinical examination and echocardiographic study (cross sectional Doppler, and colour Doppler examination) within 24 hours of and at least 6 months after implantation (range 6-26 (mean 15) months).

Setting-Multicentre study at the departments of paediatric cardiology of three academic hospitals. Tertiary clinical care of the first group of patients in the Netherlands treated by the percutaneous transvenous method.

Patients-36 patients (12 male, 24 female) mean age $8 \cdot 2$ years, (range 1.7$58 \cdot 3$ ), mean weight $25.5 \mathrm{~kg}$ (range 11$67 \cdot 8 \mathrm{~kg}$ ). The total group consisted of 46 patients. In one the implantation had failed and nine others were not available for regular follow up. All 36 patients underwent non-surgical closure of the patent ductus arteriosus with a Rashkind double umbrella prosthesis.

Main outcome measures-Diagnosis or exclusion of protrusion of the Rashkind device with or without turbulence of the blood flow with follow up of changes in protrusion and turbulence.

Results-In 17 patients the prosthesis

Department of Paediatric Cardiology, University Hospital, Leiden, The Netherlands J Ottenkamp

TN Buis-Liem

Department of Cardiology, Sophia Children's Hospital, Rotterdam, The Netherlands J Hess

Department of Paediatric Cardiology, University Hospital, Groningen, The Netherlands MD Talsma

Correspondence to: Dr J Ottenkamp, Department of Paediatric Cardiology, University
Hospital Leiden, PO Box 9600-2300 RC-Leiden, The Netherlands.

Accepted for publication 8 October 1991 protruded into an arterial lumen: the aorta in 13 and the (left) pulmonary artery in four, with turbulence in seven and two cases respectively. After six months the aortic protrusion disappeared in three, including one who had had turbulent blood flow. At the end of follow up the prosthesis still protruded into the aorta in 10 but in three the turbulence had vanished. In two of the three remaining patients with turbulence in the descending aorta the degree of turbulence had decreased. There was no lessening of turbulence in the four patients in whom the device protruded into the pulmonary artery.

Conclusions-The Rashkind double umbrella can protrude into the descending aorta and the left pulmonary artery without causing turbulent blood flow. Turbulence and the protrusion itself can disappear. Endocarditis prophylaxis

may be required for as long as the device causes turbulence.

(Br Heart J 1992;68:301-3)

Many centres use transvenous placement of the double umbrella occlusion device, ${ }^{1}$ to close a persistently patent ductus arteriosus. Transcatheter closure is feasible in most children with a patent ductus arteriosus. ${ }^{2}$ It is safe and effective, ${ }^{3}$ and offers several advantages, but it is not without complications. Residual left to right shunting after incomplete closure of the patent duct was reported in more than $30 \%$ of patients. ${ }^{34}$ With subsequent spontaneous closure of these often tiny, residual ductal leaks resulted in an incomplete closure rate of about $20 \%$ a year or more after the procedure..$^{3-5}$ Arterial complications sometimes require intravenous heparin. ${ }^{6}$ Embolisation of the device, which was reported in $15 \%$ of the patients, ${ }^{1}$ has become an uncommon event with increasing experience and improved techniques. ${ }^{58}$ Post-implantation haemolysis is a serious complication that calls for surgical removal of the device ${ }^{7}$ or placement of a second occluder device. ${ }^{9}$ Both reduce one of the main advantages of the procedure-that is, a short hospital stay. ${ }^{26}$ Only in one case endarteritis has been attributed to the procedure. ${ }^{3}$ Though it has been claimed that the occluder device does not obstruct the aorta or the (left) pulmonary artery, ${ }^{2}$ narrowing of the left pulmonary artery related to occluder device placement has been described. ${ }^{3}$ We report on the extent of obstruction that was caused by the device in the left pulmonary artery and the descending aorta.

\section{Patients and methods}

Between February 1988 and November 1989 non-surgical closure of a persistently patent ductus arteriosus was attempted in 46 patients in three academic hospitals in the Netherlands. ${ }^{89}$ Informed consent was obtained from all parents and/or patients. The treatment protocol was approved by the Ethical Review Committee of the Leiden University Hospital. The patients were not consecutive because during the study period three children were treated surgically. In one patient the procedure failed because the occluder device embolised into the right pulmonary artery. Nine patients (eight from abroad) were not available for the regular follow up, which included clinical examination, cross sectional echocardiography, and colour coded Doppler flow study.

Thirty six patients ( 21 from Leiden, 13 from 


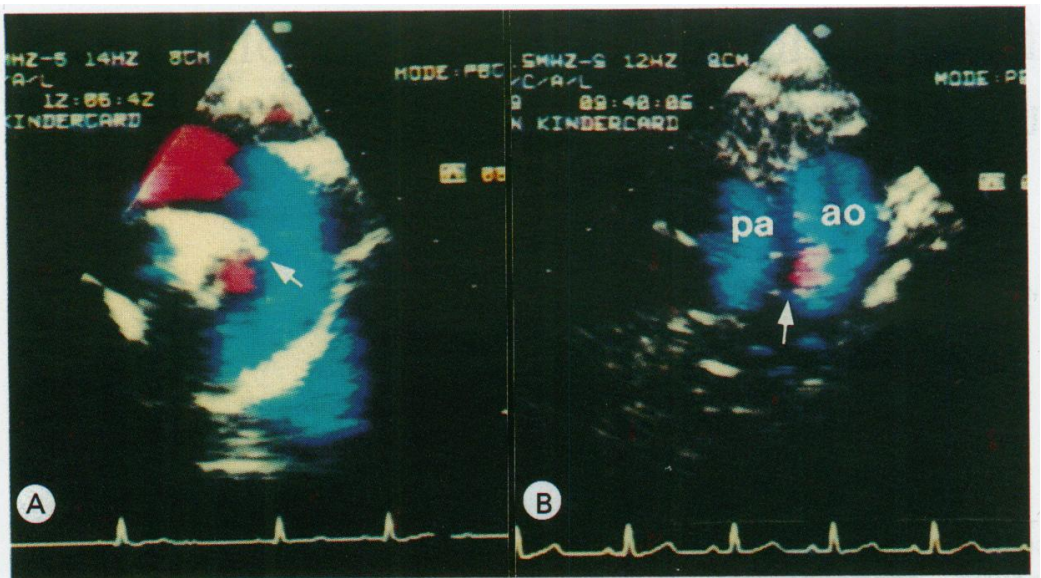

Figure 1 (A) Rashkind occluder device (arrow) protruding into the descending aorta. $(B)$ Colour coded Doppler echocardiogram showing turbulence of flow at the inner wall of the descending aorta. The arrow points to the site of the Rashkind device. ao, descending aorta; pa, pulmonary artery.

Rotterdam, and two from Groningen) participated in the study (mean age 8.2 years, range $1 \cdot 7-58 \cdot 3$ with four $>15$ years old and mean weight $25 \cdot 5 \mathrm{~kg}$ (range $11-67 \cdot 8 \mathrm{~kg}$ ). There were 12 male and 24 female patients. One also had a small ventricular septal defect and another had serious kyphoscoliosis. We used a $12 \mathrm{~mm}$ diameter device in 20 patients and a $17 \mathrm{~mm}$ diameter device in 16 according to the echocardiographically measured and angiocardiographically verified smallest diameter of the patent duct ( $12 \mathrm{~mm}$ device if $<4 \mathrm{~mm}$ ). In three patients a second device had to be implanted; in two patients after 15 and 20 months because of a considerable residual ductal leak and in the remaining patient after seven months because of a severe haemolysis that resolved subsequently.

All 36 patients underwent a complete cross sectional echocardiographic investigation (including colour coded Doppler flow) within 24 hours of the procedure and also at least six months afterwards. We used a Hewlett Packard Sonos 1000 or a Vingmed 750 system. All but three were followed up for more than six months and were restudied at the end of the

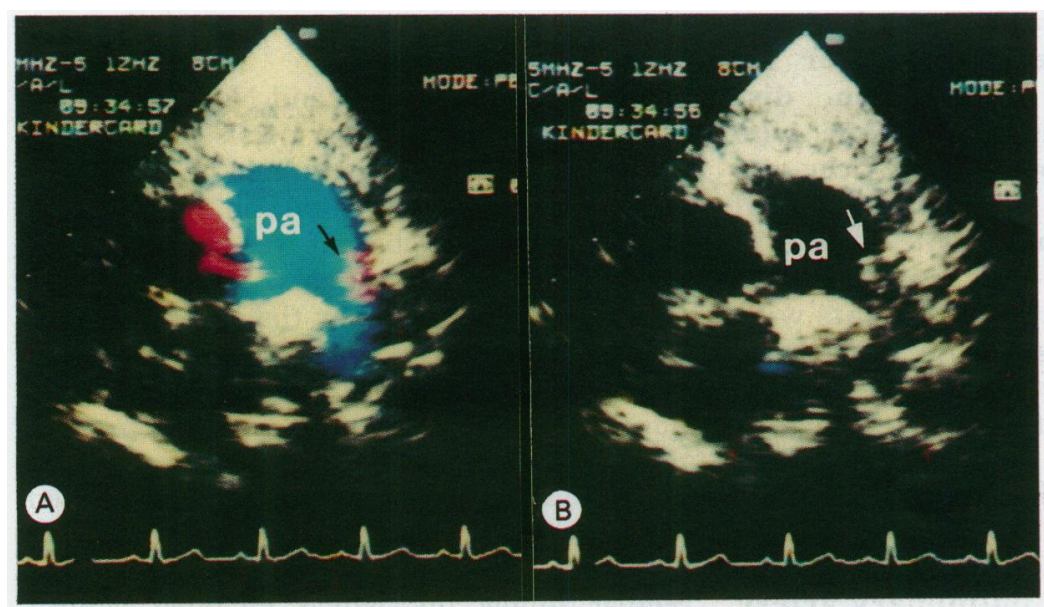

Figure 2 (A) Occluder device protruding into the left pulmonary artery (arrow). (B) Turbulence of the blood flow at the site of protrusion of the Rashkind device inside the left pulmonary artery (arrow). pa, pulmonary artery. follow-up period (mean 15 months; range 6-26 months). We especially studied the aortic arch, descending aorta, pulmonary artery, and ductus arteriosus from the suprasternal and high left parasternal short axis views and the colour coded Doppler derived turbulent flow patterns caused when the always readily visualised Rashkind occluder device protruded into the lumen of the descending aorta or pulmonary artery. We used colour flow mapping to investigate residual ductal shunting. ${ }^{310}$

\section{Results}

In $13(36 \%)$ patients the occluder device protruded into the descending aorta (fig 1A), and caused turbulent blood flow in seven (fig 1B). In six no turbulence was detected by colour coded flow imaging though the device clearly protruded. The turbulent blood flow was restricted to the inner wall of the descending aorta and was caused by one of the arms of the distal part of the device impinging on the aortic lumen. It was always unequivocally and reproducibly present. Turbulent blood flow was not seen when there was no obvious protrusion of the device. However, in several patients who had a duct with a clear aortic ampulla we found normal velocity flow towards the transducer inside the aortic end of the duct. As expected, none of the femoral arterial pulses were weakened. After six months of follow up protrusion of the device into the descending aorta had disappeared in three patients including one in whom blood flow had been turbulent. At the end of the follow up period, the device protruded into the aorta in 10 patients, but in another three patients the turbulent blood flow that had been present was no longer found. In two of the three patients with turbulent aortic blood flow at the end of the follow up period, the degree and extent of the disturbance had clearly lessened since the six month follow up. In six patients the protrusion was caused by a $17 \mathrm{~mm}$ device and in four it was caused by a $12 \mathrm{~mm}$ occluder. Protrusion of the device into the left pulmonary artery was seen in four $(11 \%)$ patients (fig 2A) and this was accompanied by turbulence in two of them (fig 2B). Both had a second $17 \mathrm{~mm}$ device implanted. In one of them, a two year old boy weighing $12 \mathrm{~kg}$, the maximal blood flow velocity measured in the left pulmonary artery was $2.7 \mathrm{~m} / \mathrm{s}$, suggesting a gradient of approximately $25 \mathrm{~mm} \mathrm{Hg}$ between the main pulmonary artery and the left branch caused by the Rashkind occluder device.

The four patients in whom a portion of the occluder device protruded into the left pulmonary artery at the start of the study showed no change over time.

In eight $(22 \%)$ patients we found residual ductal leaks. Two of them, mentioned before, with a haemodynamically significant residual shunting, underwent successful placement of a second occluder device and in two other patients the tiny leaks had disappeared six and 12 months later. The remaining four patients still have tiny residual ductal leaks and none of them have protrusion of the occluding device into an arterial lumen. 


\section{Discussion}

Catheter closure of a patent ductus arteriosus, was successful in $80 \%$ of patients after first treatment and in over $90 \%$ when successful placement of a second device in those with considerable residual ductal leaking was taken into account. ${ }^{9}$ Protrusion of a portion of the occluder device into the left pulmonary artery was described in a patient with an estimated gradient of $10 \mathrm{~mm} \mathrm{Hg}{ }^{3}$ Musewe et al described how the proximal arms of the device straddled the orifice of the left pulmonary artery in several patients but they did not report any gradient. ${ }^{4}$ In our group of 36 patients we saw protrusion of the device into the pulmonary artery in four, with a gradient of approximately $25 \mathrm{~mm} \mathrm{Hg}$ in one. During the follow up period there was no change in the numbers with narrowing of the left pulmonary artery or the extent of narrowing caused by the Rashkind occluder device. Surprisingly, we found that in 13 of the 36 patients the device protruded into the descending aorta. To the best of our knowledge, this complication has not been described before. The device seemed especially likely to protrude if a $17 \mathrm{~mm}$ diameter device was implanted in a small child. Protrusion of the device into the aortic lumen is most likely to occur in small children with a short duct who do not have an aortic ductal diverticulum to anchor the distal arms of the umbrella. Unlike the protrusion of the device into the left pulmonary artery, the aortic protrusion disappeared in three patients and in others the extent of turbulence caused by the device also decreased. Blood flow in the descending aorta was turbulent in seven patients shortly after insertion and in only three at the end of the follow up period. In two of these the extent of the turbulence had decreased. The suggested process of endothelialisation and covering with tissue of the discs of the double umbrella occluder device, leading to complete incorporation into the arterial walls, ${ }^{17}$ is likely to be slow and gradual. Our findings accord with the suggestion that with time incorporation of the device is complete, but further follow up is needed to confirm this. How long after successful and complete closure of the patent ductus arteriosus (established by colour Doppler examination) can endocarditis prophylaxis be stopped? Some advise six months, ${ }^{5}$ and others 12 months. $^{2}$ However, if tiny residual shunts are present or if the device protrudes into the aortic or pulmonary arterial lumen with turbulent blood flow at that site endocarditis prophylaxis should be continued.

1 Rashkind WJ, Mullins CE, Hellenbrand WE, Tait MA. Non surgical closure of patent ductus arteriosus: clinical application of the Rashkind PDA Occluder system. Circulation 1987;75:583-92.

2 Latson LA, Hofschire PJ, Kugler JD, Cheatham JP, Gumbiner CH, Danford DA. Transcatheter closure of patent ductus arteriosus in pediatric patients. J Pediatr 1989; 115:549-53.

3 Dyck JD, Benson LN, Smallhorn JF, McLaughlin PR, Freedom RM, Rowe RD. Catheter occlusion of the persistently patent ductus arteriosus. Am J Cardiol 1988; 62:1089-92.

4 Musewe NN, Benson LN, Smallhorn JF, Freedom RM Two-dimensional Echocardiographic and Color Flow Doppler evaluation of ductal occlusion with the Rashkind prosthesis. Circulation 1989;80:1706-10.

5 Ali Khan MA, Mullins CE, Nihill MR, Saad Al Yousef, Saud Al Oufy, Moheeb Abdullah, Al Fagih MR, Sawye W. Percutaneous catheter closure of the ductus arteriosus in children and young adults. Am J Cardiol 1989;64: 218-21.

6 Wessel DL, Keane JF, Parness I, Lock JE Outpatient closure of the patent ductus arteriosus. Circulation 1988 77:1068-71.

7 Ladusans EJ, Murdoch I, Franciosi J. Severe haemolysis after percutaneous closure of a ductus arteriosus (arterial
duct). Br Heart $J 1989 ; 61: 548-50$.

8 Rohmer J, Tynan M. Catheter closure of patent ductus arteriosus. Neth J Cardiol 1989;2:133-5.

9 Rohmer J, Hess J, Talsma MD. Sluiting van de persisterende ductus arteriosus (Botalli), door middel van catheter-interventie; de eerste 50 in Nederland behandelde patiënten. Ned Tijdschr Geneeskd 1990;134: 2347-51

10 Ludomirsky A, O'Laughlin MP, Mullins CE. Color flow Doppler low-velocity enhancement in the assessment of residual leaks across patent ductus arteriosus occlusion devices [Abstract] J Am Coll Cardiol 1990;15:186. 